\title{
PENGARUH IKLIM ORGANISASI TERHADAP STRES KERJA DAN KOMITMEN ORGANISASIONAL KARYAWAN LPD DESA ADAT JIMBARAN
}

\author{
I Made Dwiki Agustama 1 \\ I Gusti Ayu Ketut Giantari ${ }^{2}$ \\ ${ }^{1,2}$ Fakultas Ekonomi dan Bisnis Universitas Udayana (Unud), Bali, Indonesia \\ email: dwikiagustama@gmail.com
}

\begin{abstract}
ABSTRAK
LPD ialah Badan Usaha Simpan Pinjam yang dimiliki oleh desa pakraman yang berfungsi dan bertujuan untuk mendorong pembangunan ekonomi masyarakat desa melalui peningkatan kebiasaan menabung masyarakat desa pakraman, serta menyediakan bantuan kredit bagi usaha kecil dan menengah masyarakat desa. Tujuan penelitian ini untuk menjelaskan pengaruh iklim organisasi terhadap stres kerja dan komitmen organisasional karyawan LPD Jimbaran. Pengambilan sampel penelitian ini adalah dengan metode sampel jenuh. Data dikumpulkan menggunakan metode survei dengan wawancara dan kuesioner. Variabel yang diteliti adalah variabel iklim organisasi, stres kerja, dan komitmen organisasional. Responden dari penelitian ini sebanyak 69 responden. Teknik analisis di penelitian ini adalah path analysis dengan menggunakan uji sobel. Hasil analisis menunjukan variabel iklim organisasi mempunyai pengaruh yang positif dan signifikan pada komitmen organisasional, stres kerja memiliki pengaruh negatif dan signifikan pada komitmen organisasional, iklim organisasi berpengaruh negatif dan signifikan terhadap stres kerja, dan stres kerja secara signifikan mampu memediasi pengaruh iklim organisasi pada variabel komitmen organisasional. Hal ini memperlihatkan bahwa jika iklim organisasi tinggi maka stres kerja akan rendah dan komitmen organisasional akan semakin tinggi.
\end{abstract}

Kata kunci : iklim organisasi, stres kerja, dan komitmen organisasional

\begin{abstract}
LPD is a Savings and Loan Business that's owned by village that functions and has the primary aim to encourage economic development of rural communities through improving the habit of saving from the villagers, as well as providing credit assistance to small and medium-sized rural communities. The purpose of this study is to explain the influence of organizational climate on work stress and organizational commitment of LPD's employees in Jimbaran. Sampling of this study was used the saturated sample method. Data were collected using a survey method with interviews and questionnaires. The variables examined are the variables of organizational climate, work stress, and organizational commitment. Respondents from this study were 69 respondents. The technique of this analysis is path analysis with sobel test. Results from the analysis is showed that organizational climate variables had a positive and significant effect on organizational commitment, work stress had a negative and significant effect on organizational commitment, organizational climate had a negative and significant effect on work stress, and work stress was significantly able to mediate the influence between organizational climate on organizational commitment. This shows that if organizational climate is high then work stress will be low and organizational commitment will be higher.

Keywords: organizational climate, work stress, and organizational commitment
\end{abstract}




\section{PENDAHULUAN}

LPD adalah Badan Usaha Simpan Pinjam yang dimiliki oleh desa pakraman memiliki fungsi dan tujuan mendorong pembangunan ekonomi masyarakat desa melalui peningkatan kebiasaan menabung masyarakat desa pakraman, serta menyediakan bantuan kredit bagi usaha kecil dan menengah masyarakat desa, dan juga LPD memiliki peran sebagai lembaga yang dapat meningkatkan kesejahteraan masyarakat desa melalui pembangunan ekonomi kerakyatan. LPD Desa Adat Jimbaran telah berkembang secara pesat dalam beberapa tahun terakhir karena adanya kerjasama yang baik antara seluruh petinggi dan staff karyawan LPD itu sendiri dengan melibatkan peran aktif masyarakat dalam pengawasan dan pengelolaan LPD Jimbaran. LPD Desa Adat Jimbaran dalam usahanya untuk meningkatkan kualitas pelayanan dan pengelolaan yang baik dituntut agar memiliki karyawan yang mempunyai komitmen tinggi terhadap kemajuan dan kesuksesan organisasi itu sendiri. Sampai saat ini, karyawan yang telah bekerja di LPD Desa Adat Jimbaran memiliki komitmen yang cukup tinggi dimana dari hasil observasi dan wawancara yang telah dilakukan menemukan bahwa masa kerja tertinggi dari para karyawan yaitu selama 10 tahun.

Komitmen karyawan dapat dikatakan juga sebagai suatu pendekatan sikap terhadap organisasi. Komitmen karyawan terdiri dari dua penyebab yaitu sikap dan kehendak untuk berperilaku. Karyawan yang mempunyai komitmen tinggi akan dapat menerima hampir semua tugas dan tanggung jawab yang telah diberikan kepadanya dan memiliki perasaan loyalitas dan rasa memiliki terhadap organisasi. Karyawan yang memiliki komitmen yang tinggi akan ikut serta memperhatikan nasib dari organisasi mereka (Ardiansyah, 2013). Kerelaan atau kesetiaan karyawan dalam melakukan pekerjaan bisa muncul akibat dari komitmen yang terdapat dalam diri karyawan, komitmen akan terlihat ketika terjadi identifikasi dengan tugas dan internalisasi organisasi dalam diri karyawan (Adiapsari, 2012).

Mayer et al. (2015) menjelaskan komitmen organisasional paling utama dipengaruhi oleh hubungan kerja yang positif, kemudian juga dipengaruhi oleh hubungan positif organisasi terhadap lingkungan dan juga kepada orang lain, serta lingkungan kerja yang memungkinkan dan lokasi organisasi yang baik. Komitmen organisasional yang terbentuk pada setiap karyawan tidak lepas dari adanya iklim organisasi yang baik dan kondusif. Bhaesajsanguan (2010) menyatakan iklim organisasi memiliki tanggung jawab terhadap komitmen organisasional melalui kepuasan karyawan. Iklim organisasi terkait erat dengan proses menciptakan lingkungan kerja yang kondusif, sehingga dapat tercipta hubungan dan kerjasama yang harmonis diantara seluruh anggota organisasi (Suarningsih et al., 2013).

Stress merupakan suatu tanggapan penyesuaian, diperantarai oleh perbedaan-perbedaan individu atau proses psikologis yang merupakan suatu konsekuensi dari setiap tindakan dari luar lingkungan (Soegiyono, 2010). Menurut Dwipayana et al. (2015) Stres kerja dapat terlihat dari stres karyawan terhadap kondisi pekerjaannya, peran yang didapat, faktor interpersonal, perkembangan karir saat selama ia bekerja di suatu organisasi, struktur organisasi yang kurang jelas dan stres terhadap suasana organisasi. Adanya stres kerja dapat dilihat dari atasan yang sering memberikan instruksi yang tidak jelas dan bertindak tidak adil 
dalam pembagian pekerjaan kepada karyawannya. Stres kerja karyawan tersebut, jika tidak segera diatasi dapat berdampak pada perilaku yang tidak di harapkan oleh pihak organisasi, seperti kepuasan kerja yang rendah serta turunnya komitmen organisasional para karyawan.

Penelitian ini adalah untuk menguji hubungan dari variabel iklim organisasi terhadap stress kerja dan komitmen organisasional karyawan LPD Desa Adat Jimbaran. Dari penelitian awal pada LPD Jimbaran, ditemukannya suatu permasalahan yang terjadi pada LPD Jimbaran, hal tersebut terkait dalam komitmen organisasional yang dapat dilihat pada Tabel 1 .

Tabel 1.

Jumlah Karyawan LPD Desa Adat Jimbaran 5 Tahun Terakhir

\begin{tabular}{lc}
\hline Tahun & Jumlah Karyawan (orang) \\
\hline 2012 & 85 \\
2013 & 80 \\
2014 & 78 \\
2015 & 75 \\
2016 & 69 \\
\hline
\end{tabular}

Sumber: Kabag Umum LPD Desa Adat Jimbaran, 2017.

Melalui riset yang dilakukan, ditemukan beberapa alasan yang mendorong terjadinya penurunan jumlah karyawan, salah satunya adalah keinginan karyawan tersebut untuk meninggalkan organisasi sebelumnya dan mencari suasana baru dari organisasi lainnya. Fenomena ini bisa terjadi akibat dari berbagai macam faktor antara lain yaitu beban kerja yang diberikan tidak sebanding dengan upah yang diperoleh. Permasalahan komitmen karyawan pada LPD Jimbaran ini menjadi pemicu para karyawan untuk meninggalkan organisasi. Hal tersebut diatas, dapat menimbulkan suasana yang tidak nyaman dalam mencapai tujuan organisasi. Berdasarkan pemaparan di atas melatarbelakangi peneliti untuk mengetahui bagaimana pengaruh iklim organisasi terhadap stres kerja dan komitmen organisasional karyawan LPD Jimbaran.

Berdasarkan latar belakang, maka dapat dirumuskan pokok permasalahan pada penelitian ini yaitu, bagaimana pengaruh iklim organisasi terhadap komitmen organisasional karyawan LPD Jimbaran, pengaruh stres kerja terhadap komitmen organisasional pada karyawan LPD Jimbaran, pengaruh iklim organisasi terhadap stres kerja pada karyawan LPD Jimbaran, peran yang dimiliki variabel stres kerja dalam mempengaruhi hubungan iklim organisasi kepada komitmen organisasional sebagai pemediasi pada Karyawan LPD Jimbaran.

Tujuan penelitian ini yaitu untuk memberi kontribusi tambahan dan meluaskan wawasan dibidang manajemen sumber daya manusia khusus pada aspek komitmen organisasional, iklim organisasi, dan stres kerja sehingga bisa mengurangi kelemahan pada organisasi LPD atau organisasi lain dalam upayanya menuju tujuan perusahaan dan juga dapat dijadikan sebagai bahan pertimbangan dan masukan yang berkaitan dengan iklim organisasi dan stres kerja terhadap komitmen organisasional di lingkungan LPD Desa Adat Jimbaran. 
Salah satu teori dalam penelitian ini adalah The Side-Bets Theory. Teori ini menjelaskan mengenai hubungan antara karyawan dan organisasi yang didasarkan kepada kontrak dari perilaku pertukaran ekonomi menurut Weibo et al. (2010). Investasi yang dibuat oleh karyawan dalam organisasi tempat ia bekerja merupakan komitmen berdasarkan sisi taruhan. Sisi taruhan yang dimaksud adalah akumulasi investasi yang berharga dari karyawan tersebut berdasarkan manfaat atau kerugian yang akan didapat karyawan jika memutuskan untuk tetap bekerja atau meninggalkan organisasi yang terkait seperti masalah pensiun, senioritas, status sosial yang didapat, dan akses jaringan sosial yang lebih mengikat. Dalam penelitian ini juga digunakan Teori pertukaran sosial mengatakan ketika organisasi mengurus karyawan, terdapat hubungan pertukaran sosial yang dapat meningkatkan kinerja organisasi. Karyawan yang diberdayakan dan diberi pelatihan maka karyawan tersebut akan mendedikasikan semua tenaga, perasaan, dan sumber daya kognitif mereka untuk kinerja yang lebih baik (Nawaz et al., 2014).

Konsep iklim organisasi adalah sikap karyawan terhadap organisasi yang memiliki dampak cukup besar terhadap cara mereka bekerja dan bagaimana mereka berkontribusi: iklim organisasi mempengaruhi kinerja organisasi karena ini berkaitan langsung dengan motivasi karyawan (Bhaesajsanguan, 2010). Iklim organisasi yang sudah sesuai dengan keinginan karyawan dapat memberikan stimulus yang akan berhubungan dengan peran karyawan dalam kerja, status pekerjaan, rekan kerja, atasan, serta interaksi dalam kelompok kerja (Adiapsari, 2012). Komitmen organisasional dipengaruhi oleh situasi konflik kehidupan kerja (work-life conflict) di mana adanya stress kerja yang tinggi menurut Arifin et al. (2010) akan menimbulkan komitmen organisasional yang rendah. Karyawan yang terkena stress (dalam catatan tidak dapat menanggulanginya) cenderung tidak produktif, secara tidak sadar justru menunjukkan sikap malas-malasan, kebodohannya, tidak efektif dan tidak efisien, serta berbagai sikap yang dapat merugikan organisasi. Menurut Robbins (2006 : 793), stress merupakan kondisi dinamik dimana seorang individu dikonfrontasikan dengan suatu peluang, kendala (constraint), atau tuntutan yang dikaitkan dengan hal yang diinginkannya dan hasilnya dipersepsikan sebagai ketidakpastian dan tidak penting. Pendapat lainnya juga dinyatakan oleh Soegiyono (2010), bahwa stress adalah suatu tanggapan penyesuaian, diperantarai oleh perbedaan setiap individu atau proses psikologis yang merupakan suatu konsekuensi dari setiap tindakan dari luar lingkungan. Komitmen organisasional mencakup berbagai tanggapan sikap dan perilaku tentang organisasi dan kadang-kadang digambarkan hanya sebagai loyalitas. Menurut Ghosh \& Swamy (2014) komitmen organisasional adalah implikasi sikap dan tingkah laku seorang karyawan dan interaksinya terhadap organisasi yang mencerminkan bahwa karyawan tersebut merasa memiliki hubungan erat dengan organisasinya. Ackfeldt \& Malhotra (2013) menyatakan bahwa komitmen organisasi dikonseptualisasikan sebagai menciptakan multidimensi, dan mengusulkan sebuah model yang terdiri dari tiga komponen yang ditemukan dalam literatur, tiga komponen dalam komitmen organisasional tersebut adalah affective commitment, normative commitment, dan continuance commitment. 
Ketiga dimensi yang ada pada komitmen organisasional dapat mempengaruhi hubungan antara karyawan dan organisasi yang memperkerjakan mereka.

Penelitian oleh Ardiansyah (2013) menunjukkan bahwa Iklim organisasi mempengaruhi komitmen organisasional secara positif dan signifikan. Hal itu juga bisa dilihat pada hasil yang diperlihatkan oleh Aghdaie et al. (2015), yang menyatakan iklim organisasi mempengaruhi secara positif dan signifikan pada komitmen organisasional. Dari hasil-hasil diatas, dapat ditarik hipotesis ke dalam penelitian ini adalah:

$\mathrm{H}_{1}$ : Iklim Organisasi memiliki pengaruh positif dan signifikan terhadap Komitmen Organisasional

Dilihat dari penelitian yang dilakukan oleh Arifin et al. (2010) menyatakan variabel stres kerja berpengaruh positif dan signifikan terhadap komitmen organisasi. Hal ini bertolak belakang dengan hasil penelitian yang di tunjukkan oleh Karambut \& Noormijati (2012) di mana hasil penelitiannya menemukan bahwa stress kerja berpengaruh secara signifikan dan negatif terhadap komitmen organisasional. Arah hubungan negatif antara stress kerja dan komitmen organisasi menunjukkan bahwa tingkat stress kerja yang rendah cenderung diikuti dengan peningkatan komitmen organisasi. Berdasarkan penjelasan di atas maka dapat di rumuskan hipotesis sebagai berikut:

$\mathrm{H}_{2}$ : Stres Kerja berpengaruh signifikan dan negatif terhadap Komitmen Organisasional.

Organisasi yang memiliki iklim positif dan kondusif akan menciptakan kenyamanan bagi para karyawan sehingga membuat karyawan memiliki tingkat stress yang rendah yang bisa membuat karyawan tersebut semakin semangat dan berkomitmen tinggi bagi organisasinya (Paduraru \& Monica, 2014). Penelitian dari Thakre \& Shroff (2016), Ahghar (2008), dan Srivastav (2010) juga menyebutkan bahwa iklim organisasi berpengaruh negatif dan signifikan terhadap stress kerja sehingga menguatkan hasil dari penelitian sebelumnya. Dari hasil yang didapat peneliti sebelumnya, bisa ditarik hipotesis ke penelitian ini yaitu:

$\mathrm{H}_{3}$ : Iklim Organisasi memiliki pengaruh negatif dan signifikan terhadap Stres Kerja.

Dilihat dari penelitian terdahulu bahwa iklim organisasi mempunyai pengaruh pada tingkat stres kerja dan tingkat komitmen organisasional. Penelitian dari Susanty (2012), Noordin et al. (2010), dan McMurray et al. (2004) menyatakan variabel iklim organisasi memiliki pengaruh yang positif terhadap komitmen organisasional. Hasil dari penelitian Ruzungunde et al. (2016) dan Masihabadi et al. (2015) menyatakan bahwa terdapat hubungan negatif antara stres kerja dan komitmen organisasional. Penelitian yang dilakukan oleh Paduraru \& Monica (2014), menyatakan bahwa iklim organisasi mempunyai hubungan negatif dengan stres kerja. Dengan kata lain, stress kerja mempunyai peran mediasi terhadap hubungan antara iklim organisasi dan komitmen organisasional, sehingga didapat hipotesis yaitu:

$\mathrm{H}_{4}$ : Iklim Organisasi mempunyai pengaruh yang tidak langsung kepada variabel Komitmen Organisasional melalui stres kerja. 


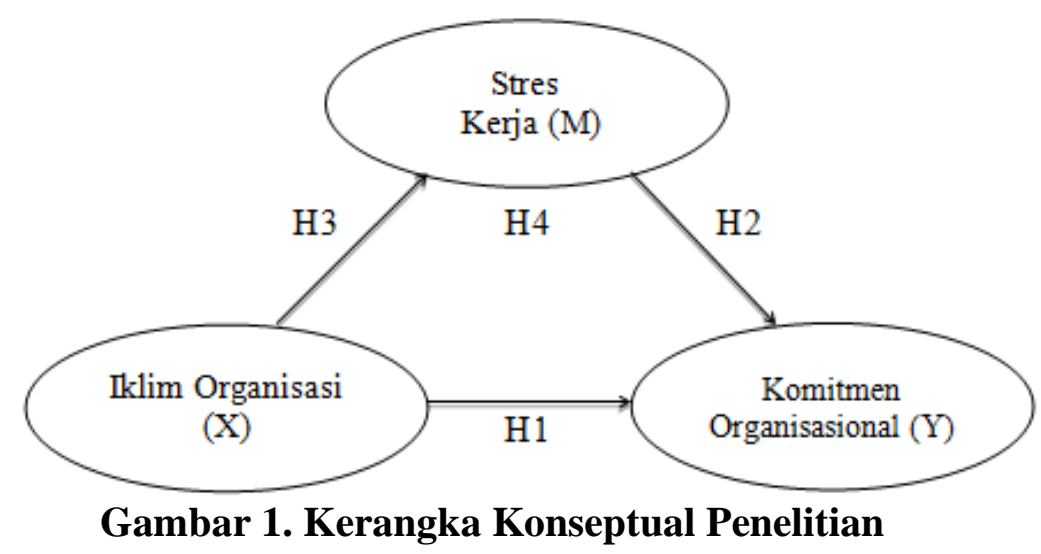

\section{METODE PENELITIAN}

Penelitian ini diklasifikasikan ke dalam penelitian kuantitatif yang berbentuk asosiatif dan juga dilakukan di LPD Jimbaran, kecamatan Kuta Selatan, Kabupaten Badung. Obyek dari penelitian yaitu variabel Iklim Organisasi, Stres Kerja, dan Komitmen Organisasional dari karyawan LPD Desa Adat Jimbaran. Pada penelitian ini terdapat tiga variabel yang dikaji, yaitu variabel eksogen dalam penelitian ini iklim organisasi (X), variabel endogen yang digunakan yaitu komitmen organisasional (Y), dan variabel mediasinya adalah stres kerja (M).

Definisi Operasional dari iklim organisasi menyatakan bahwa persepsi suasana, tekad dan harapan karyawan yang dituntut oleh sistem atau norma yang mengarahkan karyawan untuk bertindak atau bekerja sesuai dengan prosedur tertentu dalam upaya menjalankan tugas dengan tingkat keberhasilan yang tinggi. Skala/kuisioner disusun berdasarkan indikator-indikator yang dipaparkan oleh Stringer (2002) yaitu struktur, tanggung jawab, penghargaan, dukungan, dan komitmen.

Definisi Operasional dari stres kerja adalah persepsi keadaan seorang karyawan dalam mengalami situasi yang kurang baik, mengalami kelelahan luar biasa dalam melakukan berbagai aktivitas kerja yang menyebabkan tujuan dari berbagai aktivitas tersebut tidak sesuai dengan harapan atau keinginan dari karyawan tersebut. Untuk mengukur tingkat stres kerja disusun berdasarkan indikator yang telah dipaparkan oleh Dwipayana et al. (2015) yaitu kondisi pekerjaan, stress karena peran, faktor interpersonal, perkembangan karir, serta struktur organisasi.

Definisi Operasional komitmen organisasional adalah persepsi keadaan seorang karyawan yang berpihak pada suatu organisasi tertentu dan merasa bahwa organisasi tersebut merupakan hal yang sangat di inginkannya dan akan mempertahankan keanggotaan dalam organisasi tersebut. Meyer \& Allen (1991) menjelaskan indikator yang dapat digunakan untuk mengukur taraf komitmen organisasional, yaitu komitmen afektif, komitmen berkelanjutan, serta komitmen normative.

Beberapa data yang digunakan dalam penelitian ini adalah data kuantitatif berupa jumlah karyawan, umur, dan masa kerja karyawan LPD Jimbaran, serta pengolahan hasil wawancara dengan metode path analysis dan data kualitatif 
berupa hasil wawancara dari responden. Data yang digunakan dalam penelitian ini yaitu primer dan sekunder. Data primer merupakan data yang didapat dari hasil wawancara dan jawaban dari kuesioner yang sebelumnya disebarkan kepada karyawan LPD. Data penelitian yang dikumpulkan berupa persentase berasal dari data sekunder antara lain bersumber dari internal organisasi LPD Desa Adat Jimbaran, berupa gambaran umum organisasi, struktur organisasi LPD dan data jumlah karyawan LPD.

Populasi dalam penelitian ini adalah seluruh karyawan pada LPD Desa Adat Jimbaran. Dalam penelitian ini seluruh populasi dijadikan sampel. Ukuran sampel dalam penelitian ini adalah 69 responden. Metode yang digunakan adalah sampling jenuh. Metode pengumpulan data yang digunakan berupa wawancara dan kuesioner. Instrumen penelitian yang digunakan berupa kuesioner menggunakan satu skala pengukuran, yaitu skala likert. Uji validitas instrumen dipergunakan untuk memastikan bahwa nilai pernyataan pada kuesioner valid. Instrumen dikatakan valid jika koefisien korelasi setiap butir pertanyaan dengan skor total tersebut positif dan sama atau lebih besar $0,30(\mathrm{r} \geq 30)$. Uji reliabilitas instrumen dapat dilihat dengan berdasarkan nilai Cronbach alpha. Instrumen dikatakan reliabel apabila memiliki nilai Cronbach alpha lebih dari 0,6.

Teknik analisis data pada penelitian ini menggunakan teknik analisis deskriptif yang bertujuan untuk mengetahui karakteristik dan tanggapan responden terhadap masing-masing pertanyaan yang diajukan. Teknik Analisis Faktor Konfirmatori yang digunakan untuk mengestimasi pengukuran model, menguji undimensionalisasi dari masing-masing model yaitu iklim organisasi (X), stres kerja (M), Komitmen organisasional (Y). Teknik analisis jalur (path analysis) yang digunakan untuk melihat seberapa besarnya kontribusi yang dinyatakan oleh koefisien jalur pada setiap diagram jalur dan hubungan kausal atau sebab akibat yang tercipta dari variabel iklim organisasi terhadap variabel komitmen organisasional. Selanjutnya, pengujian mediasi menggunakan analisis sobel. Uji sobel digunakan untuk melihat dan menguji peran mediasi yang dihasilkan dari variabel stres kerja.

\section{HASIL DAN PEMBAHASAN}

Karakteristik responden dalam penelitian ini dapat dilihat dari profil responden yang terdapat pada kuesioner, dimana hasil dari penelitian terhadap karyawan LPD diketahui karakteristik responden meliputi usia, jenis kelamin, pendidikan terakhir, dan masa kerja yang dapat dilihat pada Tabel 2.

Karakteristik berdasarkan usia, responden atau karyawan LPD Desa Adat Jimbaran sebagian besar berusia 32-45 tahun yang dapat dilihat pada Tabel 2 dengan jumlah 41 orang dari total 69 orang karyawan atau 59,4 persen dalam persentase.

Karakteristik berdasarkan jenis kelamin, karyawan terbanyak pada LPD Desa Adat Jimbaran yaitu perempuan dengan jumlah 35 orang atau 50,7 persen. Tidak berbeda jauh dengan jumlah karyawan laki-laki yang berjumlah 34 orang atau 49,3 persen. 
Karakteristik berdasarkan pendidikan terakhir, sebagian besar responden atau karyawan LPD Desa Adat Jimbaran memiliki riwayat pendidikan terakhir yaitu SMA dengan jumlah 33 orang atau dalam persentase sebesar 47,8 persen.

Karakteristik yang dilihat dari masa kerja, mayoritas karyawan LPD memiliki masa kerja selama lebih dari 8 tahun yang berjumlah 40 orang dari total karyawan 69 orang atau dalam persentase sebesar 58,0 persen.

Tabel 2.

Karakteristik Responden

\begin{tabular}{ccccc}
\hline No. & Kriteria & Klasifikasi & $\begin{array}{c}\text { Jumlah } \\
\text { (Orang) }\end{array}$ & Persentase \\
\hline 1. & Usia & $21-31$ thn & 11 & 15,9 \\
& $32-45$ thn & 41 & 59,4 \\
& $>45$ thn & 17 & 24,7 \\
2. & & 69 & 100 \\
& Jumlah & Laki-laki & 34 & 49,3 \\
& Jenis Kelamin & Perempuan & 35 & 50,7 \\
3. & & 69 & 100 \\
& Jumlah & SMP & 7 & 10,1 \\
& & SMA & 33 & 47,8 \\
& & Diploma & 10 & 14,5 \\
& Jumlah & & 19 & 27,6 \\
4. & Sarjana & 69 & 100 \\
& & $2-4$ thn & 5 & 7,2 \\
& Masa Kerja & $5-8$ thn & 24 & 34,8 \\
& & $>8$ thn & 40 & 58,0 \\
& Jumlah & 69 & 100 \\
\hline
\end{tabular}

Sumber: Data primer diolah, 2017

Tabel 3.

Hasil Uji Validitas

\begin{tabular}{ccccc}
\hline No. & Variabel & Item Pertanyaan & Person Correlation & Keterangan \\
& & & & \\
\hline 1 & Iklim Organisasi & $\mathrm{X}_{1}$ & 0,918 & Valid \\
& $(\mathrm{X})$ & $\mathrm{X}_{2}$ & 0,926 & Valid \\
& & $\mathrm{X}_{3}$ & 0,880 & Valid \\
& & $\mathrm{X}_{4}$ & 0,904 & Valid \\
& & $\mathrm{X}_{5}$ & 0,905 & Valid \\
2 & \multirow{3}{*}{ Stres Kerja (M) } & $\mathrm{M}_{1}$ & 0,813 & Valid \\
& & $\mathrm{M}_{2}$ & 0,831 & Valid \\
& & $\mathrm{M}_{3}$ & 0,861 & Valid \\
& & $\mathrm{M}_{4}$ & 0,875 & Valid \\
& & $\mathrm{M}_{5}$ & 0,857 & Valid \\
& & $\mathrm{Y}_{1}$ & 0,848 & Valid \\
3 & & $\mathrm{Y}_{2}$ & 0,936 & Valid \\
& & $\mathrm{Y}_{3}$ & 0,939 & Valid
\end{tabular}

(Y) 
Lanjutan Tabel 3.

\begin{tabular}{|c|c|c|c|c|}
\hline No. & Variabel & Item Pertanyaan & Person Correlation & Keterangan \\
\hline & & $\mathrm{Y}_{4}$ & 0,864 & Valid \\
\hline & & $\mathrm{Y}_{5}$ & 0,872 & Valid \\
\hline & & $\mathrm{Y}_{6}$ & 0,852 & Valid \\
\hline & & $\mathrm{Y}_{7}$ & 0,953 & Valid \\
\hline & & $\mathrm{Y}_{8}$ & 0,929 & Valid \\
\hline & & $\mathrm{Y}_{9}$ & 0,826 & Valid \\
\hline
\end{tabular}

Sumber: Data primer diolah, 2017

Uji validitas instrumen dipergunakan untuk memastikan bahwa nilai pernyataan pada kuesioner sudah valid. Tabel 3. menunjukkan bahwa seluruh indikator pernyataan dalam variabel mempunyai nilai pearson correlation lebih dari 0,30. Dapat dikatakan bahwa seluruh indikator dinyatakan valid dan memenuhi syarat validitas data.

Tabel 4.

Hasil Uji Reliabilitas

\begin{tabular}{llll}
\hline No. & Variabel & Cronbach's Alpha & Keterangan \\
\hline 1 & Iklim Organisasi (X) & 0,945 & Reliabel \\
2 & Stres Kerja (M) & 0,900 & Reliabel \\
3 & Komitmen Organisasional (Y) & 0,966 & Reliabel \\
\hline \multicolumn{2}{l}{ Sumber: Data primer diolah, 2017 }
\end{tabular}

Instrumen penelitian dinyatakan reliabel apabila nilai cronbach's alpha instrumen lebih dari 0,6. Hasil uji reliabilitas instrumen disajikan pada Tabel 4. dan keseluruhan instrumen yang digunakan memiliki nilai diatas 0,6 yang memiliki makna instrumen telah reliable dan siap untuk digunakan.

Tabel 5.

Hasil Kuesioner Iklim Organisasi

\begin{tabular}{|c|c|c|c|c|c|c|c|c|}
\hline \multirow[b]{2}{*}{ No } & \multirow[b]{2}{*}{ Daftar pernyataan } & \multicolumn{5}{|c|}{ Proporsi Jawaban Responden (\%) } & \multirow{2}{*}{$\begin{array}{c}\text { Rata - } \\
\text { rata }\end{array}$} & \multirow[t]{2}{*}{ Kriteria } \\
\hline & & STS & TS & $\mathbf{N}$ & $\mathbf{S}$ & SS & & \\
\hline 1 & $\begin{array}{l}\text { Saya telah bekerja sesuai } \\
\text { tugas. }\end{array}$ & 0 & 17,4 & 13,0 & 21,7 & 47,8 & 4,0 & Baik \\
\hline 2 & $\begin{array}{lrr}\text { Saya } & \text { memiliki } & \text { tanggung } \\
\text { jawab } & \text { terhadap } & \text { pekerjaan } \\
\text { saya. } & & \end{array}$ & 0 & 11,6 & 15,9 & 21,7 & 50,7 & 4,1 & Baik \\
\hline 3 & $\begin{array}{l}\text { Saya menerima penghargaan } \\
\text { saat menyelesaikan tugas } \\
\text { dengan baik. }\end{array}$ & 0 & 17,4 & 8,7 & 30,4 & 43,5 & 4,0 & Baik \\
\hline 4 & $\begin{array}{l}\text { Saya memperoleh dukungan } \\
\text { dari atasan dan rekan kerja. }\end{array}$ & 0 & 20,3 & 11,6 & 26,1 & 42,0 & 3,8 & Baik \\
\hline
\end{tabular}


Lanjutan Tabel 5.

\begin{tabular}{|c|c|c|c|c|c|c|c|c|}
\hline \multirow[b]{2}{*}{ No } & \multirow[b]{2}{*}{ Daftar pernyataan } & \multicolumn{5}{|c|}{ Proporsi Jawaban Responden (\%) } & \multirow{2}{*}{$\begin{array}{c}\text { Rata - } \\
\text { rata }\end{array}$} & \multirow[t]{2}{*}{ Kriteria } \\
\hline & & STS & TS & $\mathbf{N}$ & $\mathbf{S}$ & SS & & \\
\hline 5 & $\begin{array}{lrr}\text { Saya senang } & \text { dengan } \\
\text { komitmen pada } & \text { organisasi } \\
\text { sehingga dapat } & \text { mencapai } \\
\text { tujuan organisasi } & \text { bersama- } \\
\text { sama. } & & \\
& \text { Jumlah } & \end{array}$ & 0 & 20,3 & 5,8 & 29,0 & 44,9 & 3,9 & Baik \\
\hline
\end{tabular}

Sumber: Data primer diolah, 2017

Sesuai dengan hasil yang didapatkan pada Tabel 5. bisa dilihat bahwa hasil dari skor rata-rata jawaban responden adalah sebesar 3,96 yang dapat digolongkan pada kriteria baik.

Tabel 6.

Hasil Kuesioner Stres Kerja

\begin{tabular}{|c|c|c|c|c|c|c|c|c|}
\hline \multirow[b]{2}{*}{ No } & \multirow[b]{2}{*}{ Daftar pernyataan } & \multicolumn{5}{|c|}{ Proporsi Jawaban Responden (\%) } & \multirow{2}{*}{$\begin{array}{l}\text { Rata } \\
\text { - rata }\end{array}$} & \multirow[t]{2}{*}{ Kriteria } \\
\hline & & STS & TS & $\mathbf{N}$ & $\mathbf{S}$ & SS & & \\
\hline 1 & $\begin{array}{l}\text { Saya merasa beban kerja } \\
\text { tidak sesuai dengan kapasitas } \\
\text { kerja karyawan. }\end{array}$ & 0 & 44,9 & 30,4 & 13,0 & 11,6 & 2,91 & Netral \\
\hline 2 & $\begin{array}{lr}\text { Saya merasa } & \text { peran dalam } \\
\text { melaksanakan } & \text { pekerjaan } \\
\text { tidak jelas. } & \end{array}$ & 0 & 36,2 & 26,1 & 27,5 & 10,1 & 3,11 & Netral \\
\hline 3 & $\begin{array}{lr}\text { Saya merasa } & \text { tidak } \\
\text { diperhatikan } & \text { oleh } \\
\text { manajemen. } & \end{array}$ & 0 & 29,0 & 49,3 & 14,5 & 7,2 & 3,00 & Netral \\
\hline 4 & $\begin{array}{l}\text { Saya merasa keamanan } \\
\text { dalam bekerja tidak dijamin. }\end{array}$ & 0 & 36,2 & 23,2 & 30,4 & 10,1 & 3,14 & Netral \\
\hline 5 & $\begin{array}{l}\text { Saya merasa pelatihan tidak } \\
\text { diberikan oleh manajemen. }\end{array}$ & 0 & 42,0 & 33,3 & 13,0 & 11,6 & 2,94 & Netral \\
\hline \multicolumn{2}{|c|}{ Jumlah } & & & & & & $\mathbf{3 , 0 2}$ & Netral \\
\hline
\end{tabular}

Sumber: Data primer diolah, 2017

Berdasarkan dari Tabel 6. didapatkan hasil skor rata-rata jawaban responden untuk stres kerja sebesar 3,02 yang digolongkan pada kriteria netral. Pada instrumen variabel stres kerja dinyatakan bahwa karyawan merasa stres kerja yang dialami rendah dalam proses menjalankan tugas-tugas yang diberikan, tetapi ada kalanya karyawan mengalami stres dalam menyelesaikan tugasnya sehingga dapat digolongkan netral.

Berdasarkan hasil yang ditampilkan pada Tabel 7. didapatkan hasil skor rata-rata dari jawaban responden sebesar 4,01 yang digolongkan pada kriteria baik. 
Tabel 7.

Hasil Kuesioner Komitmen Organisasional

\begin{tabular}{|c|c|c|c|c|c|c|c|c|}
\hline \multirow[b]{2}{*}{ No } & \multirow[b]{2}{*}{ Daftar pernyataan } & \multicolumn{5}{|c|}{$\begin{array}{c}\text { Proporsi Jawaban Responden } \\
\qquad(\%)\end{array}$} & \multirow[t]{2}{*}{$\begin{array}{l}\text { Rata } \\
- \\
\text { rata }\end{array}$} & \multirow[t]{2}{*}{ Kriteria } \\
\hline & & STS & TS & $\mathbf{N}$ & $\mathbf{S}$ & SS & & \\
\hline 1 & $\begin{array}{l}\text { Saya senang menghabiskan } \\
\text { karir di organisasi ini. }\end{array}$ & 0 & 11,6 & 13,0 & 27,5 & 47,8 & 4,11 & Baik \\
\hline 2 & $\begin{array}{l}\text { Saya merasa oganisasi ini } \\
\text { memiliki makna mendalam di } \\
\text { diri saya. }\end{array}$ & 0 & 13,0 & 21,7 & 21,7 & 43,5 & 3,95 & Baik \\
\hline 3 & $\begin{array}{lrr}\text { Saya } & \text { bangga } & \text { kepada } \\
\text { organisasi } & \text { dimana } & \text { saya } \\
\text { bekerja. } & & \\
\end{array}$ & 0 & 13,0 & 8,7 & 37,7 & 40,6 & 4,05 & Baik \\
\hline 4 & $\begin{array}{l}\text { Saya merugi apabila } \\
\text { memutuskan keluar dari } \\
\text { organisasi ini. }\end{array}$ & 0 & 11,6 & 23,2 & 21,7 & 43,5 & 3,97 & Baik \\
\hline 5 & $\begin{array}{l}\text { Saya menganggap bekerja } \\
\text { pada organisasi ini merupakan } \\
\text { suatu kebutuhan. }\end{array}$ & 0 & 13,0 & 17,4 & 20,3 & 49,3 & 4,05 & Baik \\
\hline 6 & $\begin{array}{l}\text { Saya melihat bekerja di } \\
\text { organisasi ini merupakan } \\
\text { kesempatan yang terbaik. }\end{array}$ & 0 & 15,9 & 13,0 & 24,6 & 46,4 & 4,01 & Baik \\
\hline 7 & $\begin{array}{l}\text { Saya bersedia dilibatkan } \\
\text { dalam kegiatan kerja demi } \\
\text { kepentingan organisasi. }\end{array}$ & 0 & 13,0 & 11,6 & 29,0 & 46,4 & 4,08 & Baik \\
\hline 8 & $\begin{array}{l}\text { Saya memiliki keinginan } \\
\text { untuk menghabiskan sisa karir } \\
\text { di organisasi ini. }\end{array}$ & 0 & 14,5 & 20,3 & 23,2 & 42,0 & 3,93 & Baik \\
\hline 9 & $\begin{array}{l}\text { Saya harus menyelesaikan } \\
\text { kewajiban di organisasi ini. }\end{array}$ & 0 & 15,9 & 10,1 & 33,3 & 40,6 & 3,98 & Baik \\
\hline \multicolumn{7}{|c|}{ Jumlah } & 4,01 & Baik \\
\hline
\end{tabular}

Sumber: Data primer diolah, 2017

Tabel 8.

Hasil Analisis Faktor Konfirmatori Variabel Iklim Organisasi

\begin{tabular}{|c|c|c|}
\hline Indikator variable & MSA & Keterangan \\
\hline $\mathrm{X}_{1}$ & 0,919 & Valid \\
\hline $\mathrm{X}_{2}$ & 0,900 & Valid \\
\hline $\mathrm{X}_{3}$ & 0,857 & Valid \\
\hline $\mathrm{X}_{4}$ & 0,871 & Valid \\
\hline $\mathrm{X}_{5}$ & 0,879 & Valid \\
\hline KMO & : 0,885 & \\
\hline Persentage of Variance & $: 83,648$ & \\
\hline
\end{tabular}

Sumber: Data primer diolah, 2017 
Nilai dari MSA masing-masing indikator variabel Iklim organisasi adalah > 0,5, KMO dari variabel iklim organisasi sebesar 0,885 dan nilai percentage of variance sebesar 83,648 persen, yang memiliki arti bahwa indikator dari variabel iklim organisasi bisa dipergunakan.

Tabel 9.

Hasil Analisis Faktor Konfirmatori Variabel Stres Kerja

\begin{tabular}{|c|c|c|}
\hline Indikator variable & MSA & Keterangan \\
\hline $\mathrm{M}_{1}$ & 0,855 & Valid \\
\hline $\mathrm{M}_{2}$ & 0,815 & Valid \\
\hline $\mathrm{M}_{3}$ & 0,880 & Valid \\
\hline $\mathrm{M}_{4}$ & 0,841 & Valid \\
\hline $\mathrm{M}_{5}$ & 0,804 & Valid \\
\hline KMO & : 0,838 & \\
\hline Persentage of Variance & : 75,389 & \\
\hline
\end{tabular}

Sumber: Data primer diolah, 2017

Nilai dari MSA masing-masing indikator variabel Stres Kerja adalah > 0,5, KMO dari variabel stres kerja sebesar 0,838 dan nilai percentage of variance sebesar 75,389 persen, yang dapat diartikan seluruh indikator variabel stres kerja bisa dipergunakan.

Tabel 10.

\begin{tabular}{|c|c|c|}
\hline Indikator variable & MSA & Keterangan \\
\hline $\mathrm{Y}_{1}$ & 0,941 & Valid \\
\hline $\mathrm{Y}_{2}$ & 0,927 & Valid \\
\hline $\mathrm{Y}_{3}$ & 0,954 & Valid \\
\hline $\mathrm{Y}_{4}$ & 0,973 & Valid \\
\hline $\mathrm{Y}_{5}$ & 0,978 & Valid \\
\hline $\mathrm{Y}_{6}$ & 0,964 & Valid \\
\hline $\mathrm{Y}_{7}$ & 0,955 & Valid \\
\hline $\mathrm{Y}_{8}$ & 0,928 & Valid \\
\hline $\mathrm{Y}_{9}$ & 0,945 & Valid \\
\hline \multicolumn{3}{|c|}{$\begin{array}{ll}\text { KMO } & : 0,951\end{array}$} \\
\hline Persentage of Variance & $: 79,166$ & \\
\hline
\end{tabular}

Sumber: Data primer diolah, 2017

Nilai MSA yang didapat indikator variabel komitmen organisasional > 0,5, nilai KMO 0,951 dan nilai percentage of variance sebesar 79,166 persen, yang berarti keseluruhan indikator variabel komitmen organisasional dapat digunakan.

Pengujian data dalam penelitian ini menggunakan teknik analisis jalur (Path Analysis). Merancang model analisis jalur secara teoritis ditunjukkan pada Gambar 2.

Perhitungan koefisien analisis jalur dapat dilakukan menggunakan analisis regresi pada software SPSS 22.0 for Windows dan memperoleh hasil yang ditunjukan pada Tabel 11. 


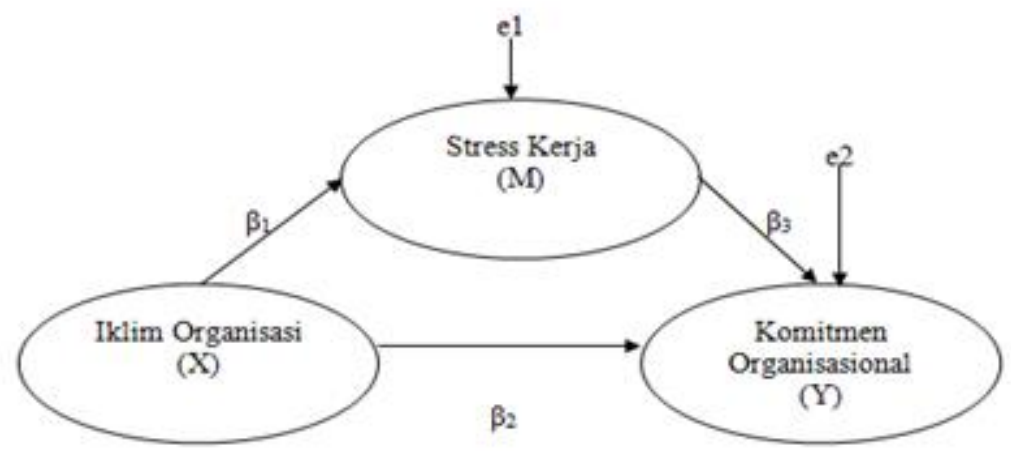

\section{Gambar 2. Model Analisis Jalur Pengaruh Iklim Organisasi terhadap Komitmen Organisasional yang Dimediasi oleh Stres Kerja}

Tabel 11.

Hasil Analisis Jalur Persamaan Regresi 1

\begin{tabular}{|c|c|c|c|c|c|c|}
\hline \multirow[b]{2}{*}{ Model } & & \multicolumn{2}{|c|}{$\begin{array}{l}\text { Unstandardized } \\
\text { Coefficients }\end{array}$} & \multicolumn{2}{|l|}{$\begin{array}{l}\text { Standardized } \\
\text { Coefficients }\end{array}$} & \multirow[b]{2}{*}{ Sig. } \\
\hline & & B & Std. Error & Beta & $\mathbf{T}$ & \\
\hline & (Constant) & $5,398 \mathrm{E}-17$ & ,089 & & ,000 & 1,000 \\
\hline & $\begin{array}{l}\text { Iklim } \\
\text { Organisasi }\end{array}$ &,- 678 & ,090 &,- 678 & $-7,543$ & ,000 \\
\hline $\mathrm{R} 1^{2}$ & 0,459 & & & & & \\
\hline F Statistik & $:$ & 56,894 & & & & \\
\hline Sig F & $:$ & 0.000 & & & & \\
\hline
\end{tabular}

Hasil substruktur 1 analisis jalur di Tabel 11. menghasilkan persamaan struktural yaitu:

$$
\begin{array}{r}
M=\beta_{1} X+e_{1} \ldots \ldots \ldots \ldots \ldots \ldots \\
M=-0,678 X+e_{1}
\end{array}
$$

Nilai koefisien regresi dari Variabel X yaitu -0,678, dapat disimpulkan iklim organisasi memiliki pengaruh negatif terhadap stres kerja.

Dari hasil substruktur 2 analisis jalur di Tabel 12. menghasilkan persamaan struktural yang diperoleh yaitu:

$$
\begin{array}{r}
\mathrm{Y}=\beta_{2} \mathrm{X}+\beta_{3} \mathrm{M}+\mathrm{e}_{2} \ldots \ldots \ldots \ldots \ldots \ldots \ldots \ldots \ldots \ldots \ldots \\
\mathrm{Y}=0,371 \mathrm{X}+(-0,627) \mathrm{M}+\mathrm{e}_{2}
\end{array}
$$

Dapat dilihat pada persamaan regresi bahwa Variabel X mendapatkan nilai koefisien regresi sebesar 0,371 yang diartikan bahwa iklim organisasi pada komitmen organisasional memiliki pengaruh yang positif, pada variabel $M$ koefisien regresi yang diperoleh $-0,627$ yang memiliki pengertian variabel stres kerja mempunyai pengaruh negatif pada komitmen organisasional.

Menguji nilai koefisien determinasi $\left(\mathrm{R}^{2}\right)$ dan variabel error (e). 
Tabel 12.

Hasil Analisis Jalur Persamaan Regresi 2

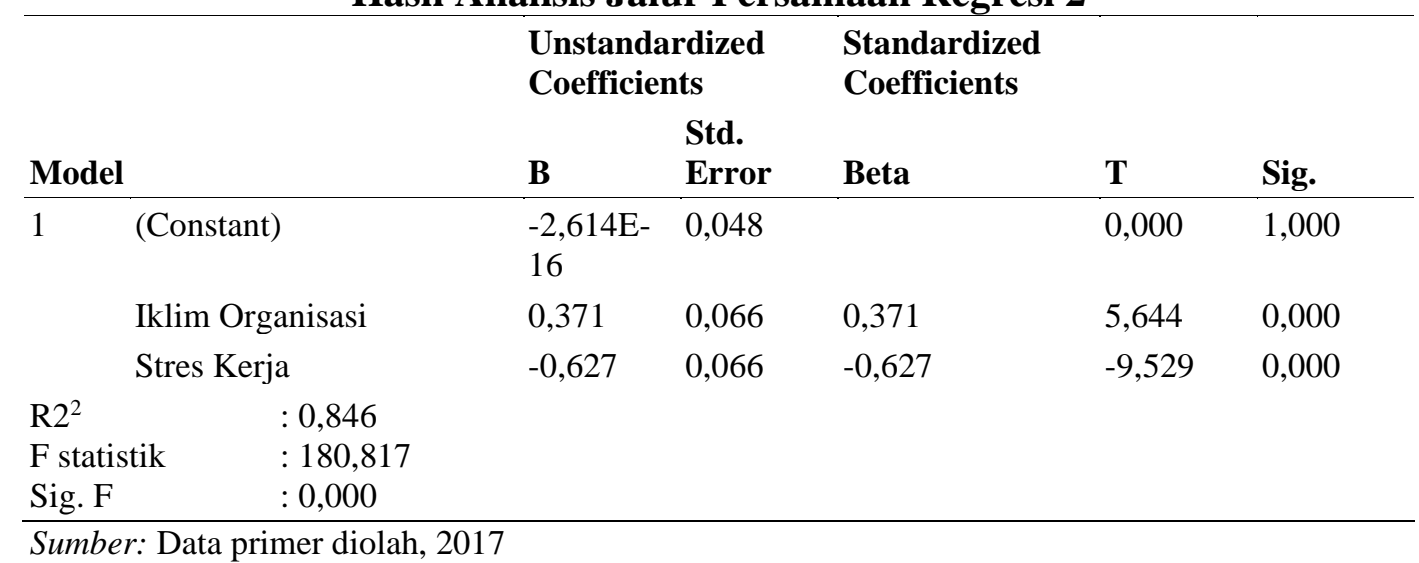

$$
\begin{gathered}
\mathrm{e}=\sqrt{1-R 1^{2}} \ldots \ldots \ldots \ldots \ldots \ldots(3) \\
\mathrm{e}_{1}=\sqrt{1-R 1^{2}}=\sqrt{1-0,459}=0,736 \\
\mathrm{e}_{2}=\sqrt{1-R 2^{2}}=\sqrt{1-0,846}=0,392
\end{gathered}
$$

Berdasarkan perhitungan pengaruh error $\left(\mathrm{e}_{1}\right)$, didapatkan hasil pengaruh error $\left(e_{1}\right)$ sebesar 0,736 dan pengaruh error $\left(e_{2}\right)$ sebesar 0,392 .

$$
\begin{array}{r}
\mathrm{R}^{2} \mathrm{~m} \quad=1-\left(\mathrm{e}_{1}\right)^{2}\left(\mathrm{e}_{2}\right)^{2} \ldots \ldots \ldots \ldots \ldots . \\
=1-(0,736)^{2}(0,392)^{2} \\
=1-(0,541)(0,154) \\
=1-0,083=0,917
\end{array}
$$

Nilai determinasi total yang didapat 0,917 dapat dibulatkan menjadi 0,92 yang memiliki makna bahwa sebanyak $92 \%$ variasi $\mathrm{Y}$ terpengaruh dari variasi $\mathrm{X}$ dan $\mathrm{M}$, nilai $8 \%$ sisanya dapat dijabarkan oleh faktor diluar selain $\mathrm{X}, \mathrm{M}$, dan Y yang tidak termuat pada model.

Berdasarkan nilai Sig. F di Tabel 12. didapat nilai Sig. F 0,000 dan $\leq 0,05$. Dengan hasil tersebut, $\mathrm{H}_{\mathrm{a}}$ bisa diterima dan disimpulkan Iklim Organisasi dan Stres Kerja memiliki pengaruh secara simultan dan signifikan kepada variabel Komitmen Organisasional. Sesuai dengan keterangan diatas, dapat dilihat jika model persamaan struktural sudah memenuhi kriteria syarat goodness of fit melalui uji F.

Kriteria pengujian untuk menjabarkan interpretasi pengaruh dari masingmasing variabel jika Sig. $\mathrm{t}<0.05$ maka $\mathrm{H}_{0}$ ditolak dan $\mathrm{H}_{1}$ diterima, jika Sig. $\mathrm{t}>$ 0.05 maka $\mathrm{H}_{0}$ diterima dan $\mathrm{H}_{1}$ ditolak. Hasil dari analisis pengaruh iklim organisasi terhadap komitmen organisasional memperoleh nilai Sig. t sebesar 0,000 dengan nilai koefisien beta 0,371. Nilai Sig. t mengindikasikan bahwa $\mathrm{H}_{0}$ ditolak dan $\mathrm{H}_{1}$ diterima. Hasil analisis pengaruh stres kerja terhadap komitmen organisasional diperoleh nilai Sig. $\mathrm{t}$ sebesar 0,000 dengan nilai koefisien beta 0,627. Nilai Sig. $t$ tersebut mengindikasikan bahwa $\mathrm{H}_{0}$ ditolak dan $\mathrm{H}_{1}$ diterima. 
Hasil dari proses analisis pengaruh iklim organisasi pada stres kerja memperoleh nilai Sig. t sebesar 0,000 dengan nilai koefisien beta $-0,678$. Dimana pada nilai Sig. t yang terdapat pada 0,000 memperlihatkan bahwa $\mathrm{H}_{0}$ ditolak dan $\mathrm{H}_{1}$ diterima.

Hasil koefisien jalur yang didapat dari hipotesis penelitian bisa digambarkan sesuai dengan Gambar 3.

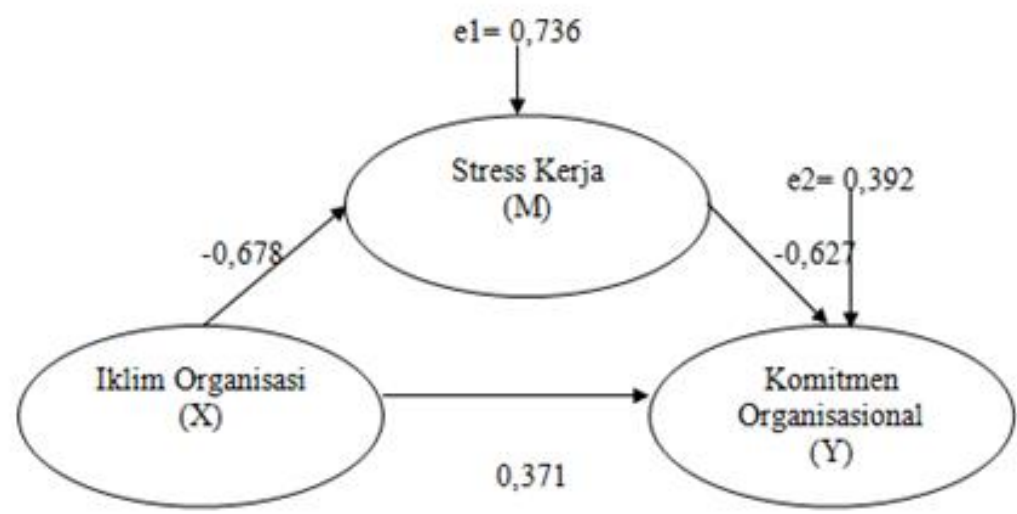

Gambar 3.Validasi Model Diagram Jalur Akhir

Diagram jalur akhir sesuai pada Gambar 3. bisa digunakan untuk menghitung berapa banyaknya pengaruh langsung, pengaruh tidak langsung serta pengaruh total sesama variabel yang dimiliki. Perhitungan pengaruh pada variabel dirangkum dalam Tabel 13.

Tabel 13.

Pengaruh Langsung, Pengaruh Tidak Langsung, serta Pengaruh Iklim Organisasi (X), Stres Kerja (M), dan Komitmen Organisasional (Y).

\begin{tabular}{llccc}
\hline \multicolumn{1}{c}{ Pengaruh Variabel } & $\begin{array}{c}\text { Pengaruh } \\
\text { Langsung }\end{array}$ & $\begin{array}{c}\text { Pengaruh Tidak } \\
\text { Langsung Melalui Stres } \\
\text { Kerja } \\
(\mathbf{Y})=(\boldsymbol{\beta 1 ~ x ~} \beta 3)\end{array}$ & $\begin{array}{c}\text { Pengaruh } \\
\text { Total }\end{array}$ \\
\hline $\begin{array}{l}\text { Iklim } \\
\text { Organisasi }\end{array}$ & $\begin{array}{l}\text { Stres } \\
\text { Kerja }\end{array}$ & $-0,678$ & - & $-0,678$ \\
$\begin{array}{l}\text { Iklim } \\
\text { Organisasi }\end{array}$ & $\begin{array}{l}\text { Komitmen } \\
\text { Organisasional }\end{array}$ & 0,371 & 0,425 & 0,796 \\
$\begin{array}{l}\text { Stres } \\
\text { Kerja }\end{array}$ & $\begin{array}{l}\text { Komitmen } \\
\text { Organisasional }\end{array}$ & $-0,627$ & - & $-0,627$ \\
\hline Sum:
\end{tabular}

Sumber: Data primer diolah, 2017

$$
\begin{gathered}
Z=\frac{(-0,678)(-0,627)}{\sqrt{\left(-0,627^{2} 0,090^{2}\right)+\left(-0,678^{2} 0,066^{2}\right)+\left(0,090^{2} 0,066^{2}\right)}}(5) \\
Z=\frac{0,425}{\sqrt{0,003+0,002+0,000032}} \\
\mathrm{Z}=\frac{0,425}{0,072} \\
\mathrm{Z}=5,883
\end{gathered}
$$


Pada hasil Uji Sobel memperlihatkan nilai akhir dari tabulasi $\mathrm{Z}=5,883>$ 1,96 yang memiliki pengertian bahwa stres kerja sebagai variabel pemediasi dinilai secara signifikan memediasi pengaruh antara iklim organisasi terhadap komitmen organisasional.

Sesuai dengan hasil pengujian hipotesis pertama, iklim organisasi mempunyai pengaruh yang positif dan signifikan kepada komitmen organisasional. Memiliki arti bahwa semakin baik iklim organisasi pada LPD Jimbaran yang dapat memberikan karyawan kenyamanan dalam menyelesaikan tugas-tugas pekerjaannya sehingga diharapkan mereka dapat mengeluarkan kemampuan terbaiknya dalam bekerja, sehingga dapat menaikkan komitmen organisasional karyawan tersebut.

Berdasarkan dari hasil pengujian hipotesis kedua, stres kerja kepada komitmen organisasional memiliki pengaruh yang negatif dan signifikan. Dimana, semakin rendah tingkat stres kerja karyawan LPD, maka hal ini menandakan semakin tinggi tingkat komitmen organisasionalnya.

Berdasarkan pada pengujian hipotesis ketiga, pengaruh iklim organisasi memiliki pengaruh negatif dan signifikan terhadap stres kerja. Semakin baik iklim kerja yang dimiliki LPD yang dapat menciptakan kenyamanan bagi para karyawan untuk melaksanakan kewajiban atau tugas yang diberikan oleh atasan, maka semakin rendah juga tingkat stres yang dimiliki karyawan yang bisa membuat karyawan tersebut semakin semangat dan berkomitmen tinggi bagi organisasinya.

Dari pengujian hipotesis keempat didapatkan hasil yaitu iklim organisasi memberikan pengaruh tidak langsung kepada komitmen organisasional melalui variabel mediasi stres kerja. Memiliki arti bahwa iklim organisasi yang baik pada LPD Desa Adat Jimbaran dapat membuat karyawan merasa nyaman dan senang dalam melaksanakan tugas dan kewajiban yang diberikan sehingga karyawan tersebut tidak merasa mendapat tekanan dan tingkat stres kerja karyawan menjadi rendah sehingga menimbulkan tingkat komitmen organisasional yang tinggi terhadap LPD Desa Adat Jimbaran. Rendahnya tingkat stres kerja dari karyawan memberikan efek pada hubungan iklim organisasi pada komitmen organisasional. Dalam hal ini, dapat dilihat bahwa iklim organisasi yang ada pada LPD Desa Adat Jimbaran sudah memiliki iklim yang positif dan kondusif sehingga membuat karyawan nyaman dalam melaksanakan tugasnya sehingga mampu menekan tingkat stres kerja karyawan. Stres kerja yang rendah mencerminkan bahwa karyawan tersebut senang dalam bekerja pada LPD sehingga komitmen organisasional karyawan dapat dikatakan meningkat. Penelitian ini mirip dengan prasangka dari peneliti dan penelitian sebelumnya.

Penelitian ini mempertegas pengaruh dari variabel iklim organisasi kepada komitmen organisasional melalui variabel stres kerja sebagai pemediasi. Penelitian ini juga memperkaya teori The Side-Bets Theory yang dikemukakan oleh Weibo et al. (2010). Teori tersebut menyatakan bahwa karyawan akan berkomitmen berdasarkan sisi taruhan. Sisi taruhan mengacu pada pertambahan investasi yang dilandaskan atas manfaat dan kerugian yang dialami karyawan apabila karyawan memutuskan untuk tetap bekerja atau meninggalkan organisasi 
dengan pertimbangan seperti pensiun, senioritas, status sosial, dan akses ke jaringan sosial yang mengikat.

Implikasi praktis penelitian ini menekankan pada manfaat nyata untuk mencegah penurunan tingkat komitmen organisasional yang dimiliki oleh karyawan LPD Desa Adat Jimbaran. Hal-hal yang bisa dilakukan yaitu LPD Desa Adat Jimbaran diharapkan mampu untuk meningkatkan kondisi dan situasi bekerja para karyawan seperti memberikan pekerjaan yang sesuai dengan kapabilitas dan tidak membebankan karyawan dengan tugas-tugas yang diluar kemampuannya, memberikan pelatihan secara berkala, serta memberikan jaminan terhadap posisi pekerjaan atau gaji yang diberikan sesuai dengan kemampuan yang dimiliki sehingga karyawan tersebut akan merasa nyaman dalam bekerja dan mampu untuk memberikan kontribusi mereka secara maksimal.

\section{SIMPULAN}

Berdasarkan hasil pembahasan penelitian yang telah dilakukan, maka dapat disimpulkan bahwa iklim organisasi memiliki pengaruh negatif dan signifikan terhadap stres kerja karyawan. Hal tersebut berarti semakin baik tingkat iklim organisasi yang didapat karyawan pada organisasi tempat bekerja, maka semakin rendah tingkat stres kerja yang dimiliki karyawan tersebut. Iklim organisasi memiliki pengaruh positif dan signifikan terhadap komitmen organisasional. Hal tersebut berarti semakin baik tingkat iklim organisasi yang didapat karyawan pada organisasi tempat bekerja, maka semakin tinggi pula tingkat komitmen organisasional yang dimiliki karyawan. Pengaruh dari stres kerja terhadap komitmen organisasional adalah negatif dan signifikan. Hal tersebut memiliki makna yaitu semakin rendah tingkat stres kerja para karyawan, maka semakin tinggi komitmen organisasional yang dimiliki. Stres kerja memediasi hubungan iklim organisasi terhadap komitmen organisasional. Artinya semakin baik iklim organisasi yang didapat karyawan, maka tingkat stres kerja yang dimiliki karyawan akan semakin rendah dan dapat menaikan tingkat komitmen organisasional yang dimiliki karyawan.

Saran dari penelitian ini yaitu LPD Desa Adat Jimbaran harus memberikan waktu bagi seluruh stakeholder untuk melakukan pertemuan yang memberikan karyawan kesempatan dalam memberikan keluhan atau kritik dan saran bagi atasan atau sebaliknya sehingga dukungan yang diberikan atasan atau rekan kerja akan mendapatkan hasil yang maksimal dan komitmen organisasional karyawan akan menjadi tinggi. Dalam menekan tingkat stres kerja karyawan, pihak LPD Desa Adat Jimbaran melalui setiap atasan harus bisa mengetahui setiap keluhan dari masing-masing bawahan yang dimiliki agar bisa memastikan karyawan tersebut merasa aman dan yakin dengan posisi yang diemban karyawan tersebut. LPD Desa Adat Jimbaran juga bisa memberikan pelatihan dengan jenjang waktu berkala untuk meningkatkan skill dan kemampuan karyawannya agar disetiap tugas yang diberikan, karyawan bisa menyelesaikan secara maksimal. LPD Desa Adat Jimbaran diharapkan mampu meyakinkan karyawannya untuk menghabiskan sisa karirnya pada organisasi ini, hal itu dapat dilakukan dengan cara memberikan tunjangan-tunjangan yang bermanfaat bagi para karyawan jika 
telah memasuki masa pensiun, seperti tanggungan kesehatan untuk seluruh anggota keluarga karyawan yang tecantum pada kartu keluarga, beasiswa bagi anak karyawan yang berprestasi di bidang akademis maupun non akademis, tanggungan keperluan dapur setiap beberapa bulan sekali, dan juga dana pensiun sesuai dengan yang ditetapkan pemerintah Republik Indonesia.

\section{REFERENSI}

Ackfeldt, A. L., \& Malhotra, N. (2013). Revisiting the Role Stress-Commitment Relationship: Can managerial interventions help? European Journal of Marketing, 47(3), 353-374.

Adiapsari, R. (2012). Analisis Pengaruh Iklim Organisasi terhadap Komitmen dengan Kepuasan Kerja Sebagai Variabel Mediasi pada Karyawan PT Tiga Serangkai Solo. Riset Manajemen \& Akuntansi, 3(5), 75-102.

Aghdaie, A., Fathollah, S., \& Behpouri, M. A. L. I. (2015). Investigating the Relation Between Organizational Atmosphere with Self-Efficiency and Organizational Commitment (Case Study Iran's Customs H eadquarters). International Review of Management and Business Research, 4(1), 177-188.

Ahghar, G. (2008). The Role of School Organizational Climate in Occupational Stress among Secondary School Teachers in Tehran. International Journal of Occupational Medicine and Environmental Health, 21(4), 319-329.

Ardiansyah, H. (2013). Pengaruh Iklim Organisasi dan Komitmen Organisasional dengan Kepuasan Kerja sebagai Variabel Intervening pada Karyawan PT Garam (Persero). Rangkuman Tesis. Surabaya: Unair.

Arifin, Z., Troena, E. ., Thoyib, A., \& Nimran, U. (2010). Pengaruh Karakteristik Individu, Stres Kerja, Kepercayaan Organisasional terhadap Intention to Stay melalui Kepuasan Kerja dan Komitmen Organisasi (Studi pada Dosen Tetap Yayasan PTS Makassar). Jurnal Aplikasi Manajemen, 8(3), 898-905.

Bhaesajsanguan, S. (2010). The Relationships among Organizational Climate , Job Satisfaction and Organizational Commitment in the Thai Telecommunication Industry. E-Leader Singapore, february, 1-15.

Dwipayana, A. D., Supartha, W. G., \& Sintaasih, D. K. (2015). Penerapan Sistem Penilaian Kinerja: Dampaknya Terhadap Kepuasan dan Stress Kerja Karyawan. E-Jurnal Ekonomi Dan Bisnis Universitas Udayana, 04(10), 643-664.

Ghosh, S., \& Swamy, D. R. (2014). A Literature Review on Organizational Commitment - A Comprehensive Summary. Journal of Engineering Research and Applications, 4(12), 4-14.

Karambut, C. A., \& Noormijati, E. A. T. (2012). Analisis Pengaruh Kecerdasan Emosional , Stres Kerja dan Kepuasan Kerja terhadap Komitmen Organisasional ( Studi pada Perawat Unit Rawat Inap RS Panti Waluya 
Malang ). Jurnal Aplikasi Manajemen, 8(3), 655-668.

Masihabadi, A., Rajaei, A., Shams Koloukhi, A., \& Parsian, H. (2015). Effects of Stress on Auditors Organizational Commitment, Job Satisfaction, and Job Performance. International Journal of Organizational Leadership, 4(3), 303314.

Mayer, C.-H., Louw, L., \& Baxter, J. (2015). 'Committed, Motivated and Joyful?' Job Satisfaction and Organisational Commitment of Managers at a South African Public Utility. Acta Commercii, 15(1), 291-303.

McMurray, A. J., Scott, D. R., \& Pace, R. W. (2004). The Relationship between Organizational Commitment and Organizational Climate in Manufacturing. Human Resource Development Quarterly, 15(4), 473-488.

Meyer, J. P., \& Alien, N. J. (1991). A three-component Conceptualization of Organizational Commitment. Human Resource Management Review, 1(1), 61-89.

Nawaz, M. S., Hassan, M., Hassan, S., Shaukat, S., \& Asadullah, M. A. (2014). Impact of Employee Training and Empowerment on Employee Creativity through Employee Engagement: Empirical Evidence from the Manufacturing Sector of Pakistan. Middle - East Journal of Scientific Research, 19(4), 593601.

Noordin, F., Omar, S., Sehan, S., \& Idrus, S. (2010). Organizational Climate and Its Influence on Organizational Commitment. International Business \& Economics Research Journal (IBER), 9(2), 1-9.

Paduraru, \& Monica, E. (2014). Sources of Occupational Stress among University Professors - A Case Study for the Romanian Universities. Revista de Management Comparat Internațional, 15(1), 49-56.

Robbins, Stephen, P. (2006). Perilaku Organisasi. Edisi Kesepuluh. Jakarta: PT. Indeks Gramedia.

Ruzungunde, V. S., Murugan, C., \& Hlatywayo, C. K. (2016). The Influence of Job Stress on the Components of Organisational Commitment of Health Care Personnel in the Eastern Cape Province South Africa. International Business \& Economics Research Journal (IBER), 15(5), 219-226.

Soegiyono, P. (2010). Pengaruh Kepemimpinan, Tuntutan Tugas dan Karir Staknan terhadap Stres Kerja dan Dampaknya bagi Komitmen Organisasi dan OCB karyawan PT. Alfa Retailindo Surabaya. Jurnal Aplikasi Manajemen, 8(2), 446-454.

Srivastav, A. K. (2010). Impact of ISO 9000 Implementation on the Organisation. International Journal of Quality and Reliability Management, 21(4), 438450 .

Stringer, R. (2002). Leadership and Organizational Climate. New Jersey: Prentice 
I Made Dwiki Agustama, Pengaruh Iklim Organisasi...

Hall.

Suarningsih, N. L. P., Alamsyah, A., \& Thoyib, A. (2013). Pengaruh Iklim Organisasi terhadap Komitmen Organisasional dan Kinerja Karyawan di Rumah Sakit. Jurnal Aplikasi Manajemen, 11(2), 233-240.

Susanty, E. (2012). Pengaruh Iklim Organisasi terhadap Kepuasan Kerja dan Komitmen Karyawan pada Universitas Terbuka. Jurnal Organisasi Dan Manajemen, 8(2), 121-134.

Thakre, N., \& Shroff, N. (2016). Organizational Climate, Organizational Role Stress and Job Satisfaction among Employees. Journal of Psychosocial Research, 11(2), 469-478.

Weibo, Z., Sharan, K., \& Wei, J. (2010). New Development of Organizational Commitment: A Critical Review. African Journal of Business Management, $4(1), 12-20$. 